\title{
MICROBIAL PREPARATION AGROMYC FOR STIMULATION OF GROWTH AND DEVELOPMENT OF DECORATIVE PLANTS
}

\section{T. L. Savchits, V. A. Timopheeva, L. A. Golovchenko, Z. M. Aleschenkova}

The beautification of cities is one of urgent problems of modern urban planning. It solves the problem of creating a favourable living environment to ensure comfortable conditions for all activities of the population [1]. When growing decorative plants it is planned to implement new technologies of cultivation, an important component of which is the use of biological preparations.

Microbial preparations based on associative microorganisms have a set of useful properties for plants: fixation of atmospheric nitrogen, improved phosphorus nutrition of plants, synthesis of phytohormones, and restriction of plant pathogens development. The use of biological preparations allows purposefully adjust the size and composition of microorganisms in the rhizosphere according to the needs of decorative plants in the conditions of urbanization.

The objective of this research is to study the effect of microbial preparation AgroMyc on the growth and development of annual flower, deciduous and coniferous decorative trees and shrubs.

Materials and methods. The research was carried out on experimental plots of open ground in the SSI "Central Botanical Garden of NAS of Belarus" (Minsk). The object of the research was microbial preparation AgroMyc, developed at the Institute of Microbiology of National Academy of Sciences of Belarus. Microbial preparation AgroMyc contains the strains of nitrogen-fixing and phosphate-mobilizing bacteria, as well as arbuscular mycorrhizal fungi (AMG). Rhizobacteria strains, that are used, produce heteroauxin - indole acetic acid (IAA), which is a stimulant of plant growth and development, in the amount of $16-25 \mathrm{mg} / \mathrm{ml}$.

Testing the effectiveness of microbial preparation AgroMyc was conducted in the experiments with annual flowering plant marigold (Tagetes erecta) of Rodos variety; coniferous decorative plant - Scotch pine (Pinus sylvestris); trees and shrubs plant - Pacific ninebark (Physocarpus opulifolius).

The introduction of microorganisms making the basis of microbial preparation AgroMyc was carry out by watering the soil (for Tagetes and Physocarpus - twice, for pine triply). The selection of soil samples was done from the rhizosphere soil (upper level) of plants; the mixed sample was prepared from three samples taken. The number of microorganisms was studied by the method of seeding soil suspension dilutions on the elective nutrient media (Ashby, Muromtsev, MSA, MPA, SA, and SAA [2]).

The effectiveness of microbial preparation AgroMyc application was determined by morphological and biometric indicators: monitoring the phenology of plants development, measurements of shoots growth, counting the number of buds, flowers, weight of the root system.

The experimental data processing was carried out according to conventional methods for biological research [3].

Thus, it was found that microorganisms making a part of the microbial preparation AgroMyc positively affect the soil biogenicity, growth and development of decorative plants. The introduction of nitrogen-fixing and phosphate-mobilizing bacteria and AMG produces a positive effect on the formation of microbial communities in the root zone of plants.

The application of microbial preparation AgroMyc produces a significant impact on the growth and development of Tagetes plants, contributing to an increase in plant height by $166.9 \%$, the formation of the root system by $162.9 \%$, much earlier beginning of budding and flowering, which led to 10 times increase in flowering productivity. The experience with Scotch pine seedlings showed that the three-fold application of biological preparation contributed to the increase in plant growth by $11.1 \%$. The stimulating effect on the growth and development of Pacific ninebark at the application of microbial preparation was $76.5 \%$.

The obtained results suggest the prospectivity of the use of microbial preparation AgroMyc for the stimulation of growth and development of decorative plants in urban plantings. 